\title{
LA CITA CON EL DESTINO PARA EL FUTURO DE LA MARCA CIUDAD JUÁREZ
}

\author{
Fate's meeting for the future \\ of the city branding for Juarez city
}

Carlos Omar Irigoyen ${ }^{1}$

Fecha de recepción: 20 de mayo de 2016

Fecha e aceptación: 18 de agosto de 2016.

1- Nacionalidad: Mexicana. Grado: Maestro en Administración con especialidad en Mercadotecnia por el Tecnológico de Monterrey. Especialización: Candidato a Doctor por Universidad de Corvinus en Budapest Adscripción: Instituto Tecnológico y de Estudios Superiores de Monterrey Campus Ciudad Juárez. Correo: iricarlos@gmail.com 


\section{Resumen}

El tema del desarrollo de marca; definiendo la personalidad y la vocación de la región, ha sido una revolución constante en la rica historia de Paso del Norte o Ciudad Juárez. Un gran reto, desde el punto de vista marca ciudad es analizar si hay incluso primero un desarrollo de marca; no puede haber un correcto mercadeo de la ciudad sin la provisión de una marca que sustente el dinamismo para promover la imagen e identidad del lugar. Ciudad Juárez se conmovió al ser declarada oficialmente el 12 de diciembre de 2015 como parte de la agenda de la Visita Papal en febrero 2016 a México; la cita con el destino, el miércoles 17 de febrero del 2016. El efecto que debe tener una visita de alto impacto -como la del Papa Francisco- deberá ser la de abonar elementos para la consolidación de la marca ciudad y no centrarse en brindar de forma cerril componentes que restan argumentos en la construcción de una imagen pública del lugar.

Palabras clave: Mercadeo de la ciudad, marca ciudad, visita papal, Juárez, Su Santidad.

\section{Abstract}

The development of city branding has been a missing part of the rich history of the city, as a village or city either. A big challenge from the city branding point of view is to analyze if there is not a city branding progress then city marketing programs are just a lie. Juarez city was touched by the official information from the Vatican state, the city was included as one of the visit places of Mexico's Papal visit in February of 2016, the destiny date, February 17. A highly regarded visit-like Pope Francis-should help to provide elements to build the concept of city branding instead of just supply non-enhancing fundamentals to strengthen the city marketing factor through city branding programs.

Keywords: city marketing, city branding, Pope's visit, Pope Francis. 


\section{Introducción}

$\mathrm{L}$

a violencia, impunidad, ciclos erráticos en su economía y la pobre imagen urbana que se ha enquistado en Ciudad Juárez, son algunas de las causas que han convertido a esta ciudad en un lugar poco atractivo para visitar.

La comunidad internacional por medio de medios de comunicación como el periódico español El País, el portal de noticias DailyMail.com de Reino Unido o gobiernos como el de Estados Unidos con sus alertas de "no viaje" a Juárez, han ayudado a consolidar una imagen ciudad poco atractiva e inclusive de acuerdo a los estudios recientes de la organización de Plan estratégico de Juárez, para algunos de sus residentes la ciudad resulta un lugar feo en el que vivir ${ }^{2}$. La ciudad está obligada a encontrar elementos que le permitan desarrollar una nueva forma de vender y promover el lugar. Muchas de las actuales teorías de desarrollo de marca ciudad se enfocan en variables muy perceptibles y que ofrezcan un extra para invertir, visitar o asentarse y radicar en ella. Es complicado encontrar en los fundamentos teóricos una explicación acerca de elementos no tangibles, como la visita de un personaje cuya influencia puede ser de impacto universal, tal y como la que ejerce el Papa Francisco. Sin duda, para el desarrollo reciente de Ciudad Juárez la visita de Su Santidad Francisco ha sido uno de los acontecimientos de mayor repercusión mediática a nivel nacional e internacional. ¿Pudiera ser posible que la visita de una personalidad de esta índole, redujera el impacto de una imagen negativa, considerando que así es la percepción en el mundo de una ciudad como Juárez? Al escuchar a SS ${ }^{3}$ Francisco hablar en la diversidad de disertaciones, hay que resaltar que sus argumentos fueron claros y fuertes sobre las condiciones del lugar, razonamientos puntuales para ahondar en el desarrollo de la marca ciudad. ¿Es Su Santidad el catalizador para el desarrollo de una nueva imagen de Ciudad Juárez o es una linda anécdota del desarrollo de la región? El fundamento de este artículo es encontrar la respuesta a esta incógnita; haciendo uso de una herramienta de análisis como es el modelo de Kazancoglu \& Dirsehan (2014) la experiencia de la ciudad y el modelo de comunicación de Kavaratzis (2014), se emitirá una conclusión sobre el efecto de la visita Papal en Ciudad Juárez.

\section{Antecedentes y conceptualización de la marca nación y la marca ciudad}

Legendario y fácilmente recordable, así es el logo de la ciudad de Nueva York creado en la década de los 70's por Milton Glaser; la frase de guerra de "I love NY" es icónica en la industria del posicionamiento de lugares. La mercadotecnia de ciudades y lugares ha sido utilizada desde mediados de los años 70's para posicionar a los diferentes lugares, el desarrollo de los grandes centros masivos de concentración de personas puntualizaban la necesidad de crear mecanismos de identidad; la ciudad "era un centro de organizado de una población, de mayor tamaño o bien de considerable relevancia más que la de un pueblo

2- En la edición de 2016, la sociedad califico con un 5.78 a los espacios públicos siendo en los espacios de la zona de la periferia donde se observan los índices más bajos de aprobación de este rubro.

3- Su Santidad. 
o la de una villa" (Balencourt \& Curado, 2012). En esos términos, se ha colocado también el mercadeo de países y la lógica indica que sí hay una asociación de países a cierta imagen, las ciudades puedan tener una oportunidad de obtener una característica intrínseca de la marca país que le permita desarrollar su propia identidad; como parte de un gran conjunto de características nacionales y que alinee la vocación y desarrollo de la región: "primero, hay que potenciar a las ciudades con condiciones ciudadanas, industriales y regionales adecuadas. De no tener estas condiciones, no hay un desarrollo equitativo y competitivo para nadie" (Scheel \& Pineda, 2014, p. 23). Hay una corriente mercadológica que está destinada a fundamentar el uso de la mercadotecnia aplicada a los países, se ha convertido en una necesidad su aplicación, "así, a día de hoy resulta evidente que el marketing y el branding se han convertido en actividades no sólo comunes sino imprescindibles para ciudades" (Alameda \& Fernández, 2012, p. 1). Es relevante discriminar la diferencia entre tres conceptos: marca, marca nación y marca ciudad; a los dos últimos los genera el primero en su más amplia conceptualización (Castillo-Villar, 2016). La necesidad del marketing de países se refiere a una conceptualización de tres ejes, el turismo, la inversión extranjera y las exportaciones (Echeverri \& Rosker, 2011). Incluso, la marca país es más un detallado de los ejes empresariales y de gobierno que sugiere la propuesta básica de beneficio de un territorio, a fin de destacar en el mercado internacional como la asociación de una multiculturalidad con la percepción que pueda fijar entre los consumidores globales. Es el juego de la representación de los grafismos de la percepción de una nación. Incluso, es conveniente inferir una diferenciación entre los conceptos de identidad e imagen, porque entre los términos de marca, imagen e identidad hay una facilidad para confundir su aplicación en las diversas conceptualizaciones de marca como por ejemplo la marca ciudad y la marca nación. De entrada imagen e identidad tienen circunscripciones diferentes; la identidad se refiere a las características inherentes de algún factor ante una situación en particular, la imagen entonces es la percepción que se tiene de la misma situación en particular (Dinnie, 2008). Cabe el ejemplo de Ciudad Juárez, la brecha entre lo que hay de identidad y de imagen es sumamente dispar, se reconoce a la población como resiliente, pero a la vez se le percibe como una comunidad violenta (Esquivel, 2012). Estos últimos conceptos son complementarios, están intrínsecos en la definición de una marca. De acuerdo a $\mathrm{AMA}^{4}$ es "un nombre, un término, una señal, un símbolo, un diseño, o una combinación de alguno de ellos que identifica productos y servicios de una empresa y los diferencia de los competidores" (American Marketing Association, 2011). Por otro lado, la metodología desarrollada por la firma croata Brandoctor (una de las 20 firmas dedicadas a la construcción de marca que está en el salón de la fama a nivel mundial en el área de mercadotecnia), señala que la marca es un conjunto de características que pasa por una progresión; que incluye la asociación de emociones, la diferenciación, características psicográficas, la autoexpresión, el mercado al cual se le comunicaran los beneficios, la accesibilidad, el valor y la participación relevante en la mente del consumidor (Brandoctor Consultants, 2011). De esta forma, la conceptualización de una marca ocurre en dos vías; la racional, con todos los aspectos señalados por la AMA y una fase emocional, la cual estudia por ejemplo Brandoctor; una tercera vía para estudiar el concepto marca seria referenciar a las acciones que provoca en el consumidor; la conjunción de los aspectos emocionales y racionales de una marca en particular; es decir hablamos se puede crear una referencia de una fase conductual en la

4- American Marketing Association, la agrupación que rige los destinos de la asociación de mercadotecnia en los Estados Unidos, autoridad a nivel mundial. 
cual pudiéramos explicar la vivencia de la marca expresada en aprobación del producto, la lealtad a la marca e inclusive hasta la compra compulsiva. De este concepto nacen las aplicaciones de desarrollo de marca ciudad y marca nación. Marca nación es definida como "la mezcla única y multidimensional de elementos que provee la nación con una diferenciación y relevancia proyectadas culturalmente para sus audiencias meta" (Dinnie, 2008, p. 15). El estudio de la marca país incluye factores propios como la visión de la marca, el alcance entre los factores como la educación, la orientación de las inversiones, el turismo, los clústeres industriales, la imagen asociada; el nombre asociado de la marca como por ejemplo si es Estados Unidos Mexicanos o simplemente México. La relevancia de códigos de expresión como el himno, las culturas prehispánicas, lo tradicional. También, abarca la conducta de los diversos grupos que cohabitan el país, la identidad, su ideología y sobre todo con una especial relevancia, la singularidad del país expresada en la conceptualización nacional que lo hace único y diferente del resto del mundo (Dinnie, 2008). Por el otro lado la marca ciudad esta referenciada como un problema de gestión urbana con una complejidad atada a cuestiones políticas y económicas (Castillo-Villar, 2016). Al estudiar las ciudades, el desarrollo de la marca de las mismas puede conducir a una gama de desarrollo de identidad y arraigo por el lugar que puede ir desde la necrópolis hasta la megalópolis; entre más grande y organizada este la ciudad, mayores perspectivas de crecimiento y dominio puede aspirar a tener la región en la era de la globalización (Harrison \& Hoyler, 2014). Para poder pretender entender y aplicar el desarrollo de la marca ciudad, es fundamental tener un amplio y profundo conocimiento de las características de la ciudad así como los mensajes y experiencias que tienen los habitantes, es decir no solamente lo que está en esquema, es trascendental administrar y darle un seguimiento puntual a la realidad que esta recibiendo cualquier habitante de la ciudad (Alameda \& Fernández, 2012). Este conjunto de características se puede visualizar en el modelo trifásico de Martínez (2014); una base social, un núcleo económico y un eje geográfico. De Quevedo, Banco y Delgado (2012) idearon un modelo sobre la reputación y desempeño de la entidad denominada ciudad. Asimismo, el hexágono de Anholt (2006) es también una clara muestra de la exigencia de reconocer el lugar y que está conformado por medio de 6 características como lo son la familiaridad con el lugar, el atractivo físico del punto, las oportunidades para el desarrollo personal y profesional, el dinamismo del lugar, la calidad del mismo y su cultura ciudadana. Un trabajo más detallado es el que ofrece Muñiz (2011); en 10 claves desglosa la complejidad de las ciudades, y es uno de los pocos exponentes del fenómeno marca ciudad que habla en un apartado de la posibilidad de equiparar a la ciudad como si se estuviese analizando un país. La compleja relación entre los diferentes actores sociales de cada ciudad, hace que se plantee la necesidad de adaptar las tradicionales herramientas de la mercadotecnia empresarial con un enfoque a nivel macro, "sus técnicas son aplicables sólo con matices en un contexto público, en el cual una ciudad es un sistema de relaciones complejas entre grupos e instituciones. Esto se hace aún más asombroso en unidades territoriales más grandes, como países" (Muñiz, 2011, p. 370). Incluso, hay herramientas más sólidas que contribuyen a un entendimiento más profundo de cada uno de los países como el Índice de competitividad Internacional. Este reporte; encabezado por el Foro Económico Mundial, refuerza la identidad de los países orientándolo en tres pilares, el desarrollo básico de las naciones, el desarrollo de un estado de eficiencia para luego alcanzar un estado de innovación (Schwab \& Sala-i-Martín, 2015). El caso de la India, representa una visión clara de cómo el reconocimiento de las virtudes de un país puede ser empleado para darle una envergadura con un propósito y orientación a una región o ciudad, y así los principales actores sociales pueden encontrar una coyuntura 
donde pueden desarrollar su potencial y a la vez convertirse en una representación clara de lo que es el país. La ciudad de Bangalore en la India, ha aprovechado las grandes disposiciones educativas que tiene para colocar en el ranking mundial a 3 de las mejores 50 universidades del mundo en el tema del desarrollo tecnológico en el desarrollo del software. A su vez, el detonar de esta industria le ha permitido una mayor influencia en la industria de la aeronáutica y la de defensa; si bien la India es reconocida a nivel mundial por su aporte al desarrollo de la industria del software, Bangalore es destacada a nivel internacional por su calificado nivel de capital humano, y es precisamente esta característica la que fortalece la representación de la marca ciudad por medio de la atracción y retención de la clase creativa; ese componente teórico que Richard Florida ha identificado como una de las metas más importantes del desarrollo de la marca ciudad: "los lugares que son exitosos en la atracción y retención de la gente que forma parte de la clase creativa prosperan, las que fallan en hacer esta tarea no lo hacen" (Florida, 2002, p. 17). Es decir, hacer que las regiones sean tan atractivas, que a las personas les llame la atención ir y establecerse por su desarrollo en determinada ciudad (Scheel \& Pineda, 2014). Hay casos como Colombia (país que ha encontrado en el narcotráfico una de las actividades más rentables por tener una amplia cartera de producción de drogas y que está respaldada por una sólida red de distribución de los mismos en el mundo, particularmente con Estados Unidos) que tiene una estigmatización palpable como nación violenta y con alto calentamiento social; una imagen negativa. Por medio de acciones puntuales entre gobierno y ciudadanos, han podido emerger como país con un enfoque diferente y a su vez, sus principales ciudades han aprovechado este planteamiento para ofrecer una perspectiva diferente al mundo, desarrollan la vocación de ser centros empresariales y de inversión sosteniendo intercambios de capital humano empleando en varias ocasiones a la academia como el vehículo de permuta de estudiantes por medio de alianzas en los sectores educativos a nivel internacional; esta condición les ha dado la oportunidad de rehacer el mercadeo de la ciudad porque están conscientes que después los inmigrantes hacen el trabajo de "embajadores del lugar"; desarrollan el papel que Kavaratzis (2014) plantea en su teoría de comunicación como la fuente terciaria de comunicación. Colombia ha ido mejorando su imagen de manera paulatina en el ámbito internacional, utilizando la perspectiva del desarrollo de marca nación reforzado con los conceptos de marca ciudad. Medellín y Bogotá son los dos ejemplos de mayor manifiesto, la primera al lograr salir del rango de las 50 ciudades más violentas del mundo (BBC Mundo, 2016) y Bogotá al ser reconocida como la ciudad creativa de Latinoamérica. Más allá de un modismo, la construcción, el desarrollo, la ejecución, la medición y el seguimiento del desarrollo de la marca ciudad, alineada con el desarrollo de marca país, es una herramienta que debe fortalecer al lugar para hacer frente a los procesos de "glocalización" que se viven en la actualidad. Las ciudades tienen una representación única, ya sea por medio de características naturales como Tebas "el valle de los reyes", Roma "la ciudad de las 7 colinas", Venecia "la reina del Adriático" o Estocolmo "la Venecia del norte". A través de la definición de ciertos atributos, hay acepciones como "Paris en un romance", "Milán es estilo", "Nueva York es energía" o "Río es cultura”. Algunos otros ejemplos hablan de la personalidad de los lugares, "I amsterdam”, "Edimburgo, la capital inspiradora", "Lyon, el lugar ideal para desarrollar tu negocio" e inclusive "Glasgow, Escocia con estilo". Directamente se observa la necesidad de la definición de una marca que ponga al lugar en un contexto universal para competir por la atracción de negocios, nuevos habitantes y en general, obsequiar un nivel de vida superior en todos los sentidos a los actores sociales; el nivel de la calidad de vida así como la infraestructura ya no serán suficientes drivers de compra de la opción de una ciudad determinada, la 
imagen clara, determinante y precisa marcaran la personalidad de las ciudad, el hacer una diferencia clara hará que se pueda lograr desarrollar un posicionamiento en la mente de los actores sociales de una comunidad (Morte, Bujedo, López, \& Fernández, 2005). La ciudad de Ámsterdam en Holanda, ha hecho un espléndido trabajo en el tema del desarrollo de la marca ciudad. Propuso un enfoque de 16 dimensiones; la ciudad del conocimiento, de los eventos, de las compras, de la vida nocturna, la ciudad artística, la ciudad compacta, su arquitectura, una ciudad vivible, el lugar del capital humano, la temática relativa a sexo y drogas, la ciudad de los negocios, un lugar para inversiones, la ciudad de los canales, el punto de las convenciones, el centro de coordinación y la ciudad residencial. El organismo de creación de marca ciudad, definió 6 dimensiones prioritarias; ser la ciudad cultural, la ciudad de los canales, la ciudad de las convenciones, la ciudad del conocimiento, la ciudad de los negocios y la ciudad residencial. Mediante investigación de mercado, lograron determinar que en las tres primeras dimensiones de estas prioridades eran ya muy fuertes en su posicionamiento internacional y por lo tanto debían trabajar para mantener esa posición; en las subsecuentes tres eran "débiles" y necesitaban trabajos estructurales para poder alcanzar niveles de desempeño previamente establecidos. Al mismo tiempo, la ciudad fijó la creatividad, la innovación y el espíritu de comercio como los valores a inculcar en el posicionamiento entre sus mercados meta (Saffery, 2010). No es en vano que Holanda sea muy competitivo a nivel mundial; su población tiene un ingreso per cápita de \$51,000 dólares, una nación ubicada en la máxima fase de desarrollo competitivo, un estado de innovación y colocada como nación en el quinto lugar de competitividad mundial. Al valorar las 6 dimensiones prioritarias del desarrollo de marca ciudad de Ámsterdam, hay un reflejo de su marca nación. Utilizando los número del Índice Global de Competitividad; al hablar de ser "la ciudad cultural", las calificaciones respecto a la calidad de la educación formal van por encima de 5.4 de un máximo de $7^{5}$, quedando en el rango de los mejores 8 países del mundo. Aludiendo a la ciudad de los canales, la infraestructura es de las mejores a nivel mundial e incluso, en los accesos vía marítima está catalogada como la mejor de todo el mundo. Cuando se expresan como aspirante a ser "ciudad de las convenciones", se debe destacar que tienen la infraestructura necesaria para la recepción y logística de visitantes, ejemplificado con el acceso al internet, el cual esta referenciado de muy alto nivel al estar clasificado mundialmente como el tercer mejor en esta especialidad. De las últimas tres características (en las cuales hay una suposición de debilidad); aspirar a ser la ciudad del conocimiento, de los negocios y la ciudad residencial, hay elementos para asegurar que el desarrollo de la marca ciudad tiene un alto nivel de competitividad plenamente respaldado por la marca Holanda. Como muestra, el país tiene un ranking de 209 patentes por millón de población, con lo que se demuestra en indicadores la creación de conocimiento; inclusive la calidad de sus investigaciones esta enlistada como la sexta mejor en el mundo. Al momento de evaluar su capacidad de crear la ciudad de los negocios, Holanda respalda plenamente la postura, en todos los aspectos considerados para crear un ecosistema de negocios está dentro de los 12 mejores del mundo, a excepción del factor que considera la cantidad de proveedores locales, el cual está en el lugar 17. Para poder abrir un negocio solamente se requiere hacer un proceso de 4 pasos y tener un compás de 4 días para legalmente operar un negocio; una estructura muy ágil, una operatividad que favorece el desarrollo de la cultura empresarial. Del fortalecimiento de la ciudad residencial; hay una estadística que afirma que el trabajo que hacen por retener y atraer nuevos habitantes a la zona tiene una perspectiva de ser el lugar

5- En el índice de competitividad, la mayor calificación es un 7. 
13 de la lista de 140 países. Todos los datos anteriores nos indican la importancia de desarrollar un plan de marca ciudad que este respaldado por un plan de marca nación; es una simbiosis, en teoría no pueden coexistir marcas ciudades fuertes sin un desarrollo sostenido de marca nación (Schwab \& Sala-i-Martín, 2015). En los siguientes apartados se analizará como la visita de una personalidad -en específico el Papa Francisco- a Ciudad Juárez puede ser el detonante de muchos cambios en la marca ciudad, e inclusive alterar el desarrollo de la marca país. Un ejemplo de cómo se puede llegar al desarrollo de la arca ciudad atravesando primero el descubrimiento y desarrollo de la marca nación.

\section{Juárez, la historia detrás de los años}

Para aplicar el concepto de marca ciudad al lugar de estudio, hay que detallar algunos puntos de la historia de la ciudad de objeto de investigación. Juárez es una ciudad que localizada al norte del estado de Chihuahua y fue fundada el 8 de diciembre del año de 1659 por Fray García de San Francisco con el nombre de La Misión de Nuestra Señora de Guadalupe de los Mansos de Paso del Norte (Castañeda, 2015). En el siglo XVIII se observa una dualidad de culturas, por un lado, los ya existentes Mansos, y por el otro, un grupo con claras habilidades para el desarrollo de la agricultura denominado Piros. El resultado de esta fusión es la riqueza de lo que, en principio, fue Paso del Norte. En 1751, la población de los Mansos se redujo y de esta forma los Piros se convirtieron en el grupo dominante de la región (Reynolds, 2011). El 2 de febrero de 1848, con la firma de los Tratados de Guadalupe-Hidalgo, se dio la condición que al día de hoy es una de sus principales fortalezas, la disposición geográfica que la convirtió en un punto fronterizo entre México y Estados Unidos. En 1865; la Presidencia de la República huyó de la intervención francesa en el centro del país, busco y encontró refugio en el Paso de Norte. El general Porfirio Díaz en 1885 declaró a Paso del Norte como zona de libre comercio y aun cuando esta condición sólo fue sostenida durante 6 años, resultó en un gran impulso comercial e industrial para la región, que para ese tiempo contaba con modernos sistemas de ferrocarriles e innovaciones como el telégrafo, condiciones que le ayudaban a tomar una ventaja competitiva beneficiada por su localización geográfica. En 1888, el presidente Porfirio Díaz anunció que la Villa Paso del Norte tomaría el nombre de Ciudad Juárez. En 1909 en este punto fronterizo, se celebró por primera vez una reunión entre los presidentes de México y Estados Unidos, el general Porfirio Díaz y William Taft respectivamente. Solamente dos años después, Díaz renunció al poder después de 34 años en el mismo; con este acto originado en Juárez comenzaría el periodo histórico de la Revolución Mexicana. Al término de la misma en 1920, Estados Unidos promulgó la ley Volstead ${ }^{6}$. Gracias a esta disposición legal se desarrolló en principio la vocación turística de nuestra ciudad; miles de norteamericanos cruzaban la frontera diariamente buscando diversión y alcohol, una situación que no tenían disponible para su modo de vida al otro lado de la frontera. Uno de los efectos colaterales de esta situación fue el desarrollo paralelo de otro tipo de negocios como el contrabando de alcohol, restaurantes, tiendas de venta de cigarros y la prostitución; todos estos factores alentaron el crecimiento poblacional de la frontera que, en tan solo una década, incrementó en más de un 10\% (Flores Simental, 2013). En 1929, se presenta el período de la Gran Depresión en Estados Unidos y 
con ello queda muy claro el factor de codependencia entre ambas ciudades. Una década después el sector primario; se convierte en el ancla del desarrollo económico de la región. La siembra del algodón situó a la región del Valle de Juárez como la segunda más fuerte a nivel internacional, solamente detrás de Egipto. Esta condición no pasa desapercibida para las partes comerciales de Estados Unidos y con la creación del programa Braceros ${ }^{7}$, lograron atraer a los mexicanos para que trabajaran en Antonhy, Roswell, Lovington y Pecos(Farworkers.org, s.f.). Esto afectó a la economía regional, al grado de que en algún momento había suma necesidad de manos que trabajaran en los campos fronterizos; había fuentes laborales no así trabajadores; se abria la puerta a los movimientos migratorios de otras regiones del país a la zona fronteriza de Chihuahua, en particular a Ciudad Juárez. La segunda guerra mundial ajusto de forma natural esta necesidad. El desarrollo económico volteó su orientación hacia la industria del entretenimiento; restaurantes, lugares para bailes eróticos, bares, cantinas, cabarets y salones de baile establecidos en la avenida Juárez y que le dieron rumbo a la internacionalización del entretenimiento en nuestra ciudad. En su momento fueron muy populares lugares como el Tivoli, Lobby, Chairmont, La Fiesta, La Cucaracha, El Guadalajara de Noche, El Waikiki, el Molino Rojo y El Follies, que fueron bautizados como aquellos en los cuales se hacia la fiesta(Sandoval \& Pena, 2005). Paralelo a este desarrollo se inició la era del "divorcio exprés", un desarrollo empresarial amparado en atraer personalidades como Marilyn Monroe que por ejemplo en cuestión de menos de un día se divorció en nuestra localidad de Arthur Miller, la época dorada del divorcio exprés; breves y expeditos procesos de disolución de actos matrimoniales de la mano de personalidades como Artemio López Bustamante o Eugenio Calzada; personaje fronterizo que llego a ser llamado en la frontera "el rey del divorcio" (Salas, 2014). En 1964, el presidente Gustavo Díaz Ordaz ordenó la modificación de la ley de población, prohibiendo el desarrollo de este tipo de actividades jurídicas del orden familiar. Es en esta misma época; y como panacea del desamparo al desarrollo turístico que se implementa en Juárez el programa Maquiladora. Este esquema era un modelo innovador para la etapa de modelos de desarrollo industrial mundial cuya base era muy simple, atraer grandes compañías para la fabricación de partes automotrices, ropa, equipo médico, equipos de comunicación y conforme fue más palpable el desarrollo tecnológico de los productos de uso cotidiano, la industria se abrió para celulares, computadoras, electrónicos y el turismo médico; la clave en el proceso es fabricar en esta localidad a bajo costo y exportar las piezas -ya transformadas- a sus lugares de origen. Es a la par del desarrollo de esta industria que se acentúan los movimientos de migración de las diferentes partes de la república mexicana a la frontera. En 1985, el gran terremoto del Distrito Federal empuja a muchos habitantes del lugar a buscar nuevos sectores de residencia. En 1989, auspiciados por las condiciones de falta de trabajo en sus localías se dan los movimientos poblacionales de Torreón, Gómez Palacio y Zacatecas hacia la frontera chihuahuense. Por esta misma razón; en 1991 se dieron fuertes movimientos poblacionales de Veracruz a Juárez. Luego, desde 2002 y hasta la fecha; motivados por el "sueño americano", personas de Oaxaca, Chiapas, Guerrero, Michoacán e inclusive de naciones centroamericanas, han hecho de Juárez

7- Programa desarrollado por las autoridades norteamericanas para atraer a recolectores mexicanos y cosechar el algodón a cambio de beneficios legales como la estancia en el país, un mejor salario y un estilo de vida muy diferente al que podían lograr en Juárez o la Laguna, los dos principales puntos de desarrollo de la agricultura cercanos a la frontera.

8- Se le llama a la condición de irse sin papeles de autorización de cruce y permanencia (ilegales) a Estados Unidos para poder trabajar y vivir en ese país con la esperanza de proveer de ingresos estables a sus comunidades de origen por medio del envío de manera constante de dinero, lo que se llama "remesas". 
un lugar de paso en sus pretensiones de residencia. Si logran cruzar al país del norte; allá se quedarán, en caso de no poder hacerlo, regresarán a la frontera a buscar trabajo o en su defecto a buscar otra oportunidad para intentar de nueva cuenta el cruce ilegal a los Estados Unidos. Es en este contexto, la forma en como la ciudad nunca ha tenido el enfoque de desarrollar el concepto de marca ciudad, es debido en gran parte a que el desarrollo económico siempre ha opacado las oportunidades del desarrollo social y de marca(Limas, 2011). Por eso, se puede afirmar que la ciudad siempre ha gozado la mayor parte de su historia de una realización económica extraordinaria y que no está respaldada de manera robusta por la inercia social y de infraestructura. Estas condiciones aunado al problema de la inseguridad, han dado como resultado una marca débil o en el mejor de los casos inestable, en un entorno globalizado cada vez más agresivo y demandante en cuestiones de competitividad e imagen.

\section{E1 caso de Ciudad Juárez desde la óptica del modelo de comunicación de Mihalis Kavaratzis.}

La base del planteamiento de Kavaratzis (2014) se fundamenta en tres pilares; comunicación primaria, secundaria y terciaria. La comunicación primaria se refiere a que los mensajes intencionales están representados por la experiencia que la marca de la ciudad transmite a los ciudadanos. Son vitales cuatro aspectos en este tema, el urbanismo, la infraestructura, la organización y la conducta.

Si habla del urbanismo, la ciudad tiene varios puntos de interés; el parque del Chamizal, la Plaza de la Mexicanidad, el Museo de Arqueología, el parque del Trepachangas, Camino Real, el parque Central Hermanos Escobar, el zoológico de San Jorge, el museo interactivo de La Rodadora y el parque nacional de las Dunas de Samalayuca. La infraestructura urbana es el punto más retador en este momento para la urbe, aunado al deterioro de las calles y avenidas que componen las vías de comunicación de la ciudad, el transporte público presenta un atraso de por lo menos de 30 años en equipamiento. La ciudad está considerada como uno de los puntos claves en el desarrollo comercial y de logística con los Estados Unidos. A pesar de la ventaja competitiva que tiene por ser frontera, el mismo gobernador del Estado declaró al respecto de la movilidad urbana: "Juárez tiene una gran necesidad de ello, porque siendo una ciudad industrial, vigorosa y con una gran infraestructura logística para atender hasta mercancías que trascienden incluso al continente, no cuenta con un sistema de transporte público adecuado a sus necesidades" (El Devenir staff, 2011). La variable de la organización ha sido muy confusa hasta el momento, son pocos los mecanismos para hacer contacto con funcionarios públicos, pero destacan dos de ellos: las reuniones con Cámaras Empresariales y las Audiencias Públicas ${ }^{9}$. Finalmente, el factor referente a la conducta tiene mucha inconsistencia en su aplicación en nuestra frontera, los eventos se diseñan para un cierto segmento de la población y se descuidan la atención sobre algunos grupos propios del desarrollo social fronterizo; la Feria de Juárez y la participación en el torneo nacional de futbol del equipo Bravos se perfilan como eventos que son unificadores de criterios en la convivencia social fronteriza. El fenómeno del futbol en la frontera, expresado en forma de un campeonato por la franquicia de reciente creación

9- Las Audiencias Públicas son las reuniones con ciudadanos en lugares como parques comunitarios o auditorios. Las reuniones con Cámaras Empresariales son aquellas que son llevadas a cabo con sectores muy especializados de la sociedad y por lo regular tiene carácter de encuentros privados. 
denominada Bravos; un título que fue conseguido en menos de 6 meses de existencia puso de relevancia nacional e internacional a la frontera; incluso su dueña Alejandra De la Vega, acotó en la más reciente visita en febrero de 2016 del Presidente Enrique Peña Nieto: "juntamos un grupo de inversionistas, compramos un equipo de futbol y en seis meses lo hicimos campeón, así somos la gente de Juárez"10. La escala secundaria de comunicaciones del modelo de Kavaratzis refiere sus alcances a "las comunicaciones oficiales de las autoridades gubernamentales (intencionales)... en la forma de publicidad, relaciones públicas, diseño" (Kavaratzis, 2014, p. 2). En octubre de 2013, Enrique Serrano asumió la presidencia de Juárez para el período 2013-2016. Su plan de gobierno incluyó todo un capítulo dedicado a la Comunicación Social municipal con objetivos muy claros respecto a la función relativa de esta área en el desempeño de su gestión. El desarrollo de la comunicación tenía como objetivo "mantener lineamientos claros y objetivos para el manejo de la Imagen Institucional y de la Información del Gobierno Municipal hacia la ciudadanía" (Gobierno Municipal de Ciudad Juárez, 2013, p. 60).

Las estrategias que fueron elaboradas para poder llegar a estos objetivos fueron:

Establecer un Manual de Imagen Institucional especificando formas y contenidos. Mantener una línea periodística objetiva y clara en la redacción de Programas, Proyectos y obras del Gobierno Municipal 2013-2016.

De igual forma se establecieron 4 líneas de acción muy puntuales:

Unificar criterios mediante la creación de vocerías que generen y comuniquen cada acción específica del Gobierno.

Generar Comunicados de Prensa de las acciones de Gobierno, así como de los resultados obtenidos por su ejecución.

Difundir en tiempo y forma las Campañas Publicitarias e Informativas. Elaborar una Agenda de Medios para entrevistas en vivo de los Directores o Representantes de los Gobiernos.

"Estos Programas serán atendidos principalmente por la Coordinación de Comunicación Social, conforme al Reglamento Orgánico de la Administración Pública del Municipio de Juárez, Estado de Chihuahua"(Gobierno Municipal de Ciudad Juárez, 2013, p. 60).

De acuerdo al sistema de indicadores de Así estamos Juárez, las 5 principales actividades para el esparcimiento y uso del tiempo libre en los juarenses son ver televisión (83\%), escuchar la radio (66\%) ir a un centro comercial (47\%), ver una película en la casa (42\%) e ir a un cine público (31\%). Actividades como ir a parques públicos, espacios culturales y espectáculos deportivos, alcanzan entre los tres un 15\% (Plan Estratégico de Ciudad Juárez, 2015). La percepción de espacios públicos y áreas verdes han sido catalogadas como insatisfactorias, la calificación fue de 6.19 sobre 10, la más baja en los últimos 5 años. El 39\% de la población tiene la creencia que el problema de inseguridad es el más fuerte de la ciudad, esto refleja la percepción generalizada 
de que, aún y con los esfuerzos publicitarios por concientizar a la población de una baja sensible en los índices delictivos; Juárez sigue siendo una ciudad violenta. Los servicios mejor evaluados son los de recolección de basura con un 8.54, mientras que los peor evaluados por cuarto año consecutivo son el mantenimiento de calles y avenidas con un 5.85; lo anterior a pesar de que en 2013 el Cabildo de la ciudad aprobó un crédito por más de \$2,000 millones de pesos mexicanos y cuya inversión aún no ha logrado ser traducida en los beneficios percibidos por la población. La comunicación terciara se basa en "la publicidad que se desarrolla de boca en boca, muchas veces influenciada por los mensajes que emanan de los medios de comunicación"(Kavaratzis, 2014, p. 2). Mucho del desarrollo en redes sociales es donde los cibernautas quieren desarrollar la imagen de Juárez, como una ciudad con una nueva marca; un lugar lleno de gente talentosa y bien intencionada; este trabajo no ha sido aprovechada por la instancia gubernamental que apenas alcanza una calificación de 5.6 en su desarrollo como líder de la comunidad (Plan Estratégico de Ciudad Juárez, 2015). Todas las condiciones sumado a factores como la corrupción, la impunidad, la violencia, la desaceleración económica y los bajos salarios ofrecidos en la mayoría de las fuentes laborales han desarrollado una percepción débil tanto para los visitantes como para los ciudadanos locales respecto a la marca Ciudad Juárez; si bien la comunicación primaria y secundaria han sido hasta cierto punto administrables, la percepción expresada en la comunicación terciaria ha reflejado una fragilidad en el arraigo, proyectando una imagen difusa y convenenciera de lo que en realidad es nuestra localidad. ¿Es posible desarrollar un sólido programa de mercadeo de la ciudad cuando aún ni siquiera se tiene con certeza el significado y vivencia de la marca ciudad? Esta pregunta lleva a la reflexión de cómo se puede desarrollar un programa exitoso de comunicación, en la realidad hay tantos temas de comunicación que no han sido lo suficientemente bien divulgados para que la ciudadanía conecte con su experiencia de vivir y desarrollarse en esta ciudad aumentando su nivel de vida. ¿Se podrá tener algún resultado diferente con la visita de un personaje -como el Papa Francisco- que tiene una fuerte influencia a nivel mundial alterando modelos de desarrollo que tienden a ser cada vez más obsoletos? Para explicar el desarrollo de esta pregunta se evaluará el desarrollo del modelo denominado Experiencia de la ciudad desarrollado por Kazancoglu y Dirsehan (2014), teniendo como referencia y previa explicación el caso de Cuba que está haciendo la apertura de su sistema económico y social en el mundo presentando todo un reto para el desarrollo de la marca nación y su implementación a nivel de marca ciudad.

\section{Cuba, la posibilidad de la evolución de la marca nación al desarrollo de la marca ciudad.}

En los últimos 38 años son tres los Papas que han tenido por lo menos más de 40 días de pontificado ${ }^{11}$; Juan Pablo II, Benedicto XVI y Francisco. De ellos, Juan Pablo II ha sido designado como el Papa Viajero al realizar 140 viajes al exterior; desde su primer viaje a México tras su ordenamiento en 1978, y hasta el último que hizo en 2004 al norte de Italia, se contabilizaron un gran total de 250 (ACI Prensa Vaticana, 2015). Visitó países tan inusuales como AltoVolta, Congo, Kenia en África; con altos niveles de islamismo o con poblaciones de bajo perfil católico como Paquistán, Japón, Nigeria, Belice, Corea del Norte, Tailan-

11- Para efecto de análisis no se tomará en cuenta el Pontificado de Juan Pablo I al solo durar 33 días en los que inclusive no registro algún viaje pastoral. 
dia, Marruecos, Singapur o Albania; todos ellos fueron testigos de los argumentos papales; pero si hubo alguno que lo sintió de manera determinante fue la isla de Cuba. Juan Pablo II a su muerte el 2 de abril del 2005, dejaba de ser el Obispo de Roma estando al frente de la grey católica por un ciclo de 26 años con 18 días. Tan sólo 17 días después, Joseph Ratzinger fue electo como el nuevo Papa; la misión de sustituir a una personalidad tan mediática como Karol Wojtyla era una tarea ardua e impresionante. Tomo el nombre de Benedicto XVI y se desempeñó como el Papa número 265 de la historia. En los 7 años que estuvo al frente de la iglesia como Obispo de Roma, Benedicto XVI visitó lugares como Alemania, Polonia, Jordania, Israel, Croacia, Inglaterra, México y por supuesto Cuba. De manera sorpresiva, el mundo se convulsionó ante el anuncio de Benedicto XVI de renunciar al Pontificado como una decisión estrictamente personal; un hecho inédito desde 1294, un suceso que tendría carácter oficial a partir del 28 de febrero del $2013^{12}$. Una nueva etapa de orfandad de liderazgo para la Iglesia Católica, y por supuesto la elección mediante un Conclave de la persona que dirigiría los destinos de la religión más reconocida en el mundo occidental. Así de esta forma, el 13 de marzo del 2013, el Arzobispo de Buenos Aires Jorge Bergoglio (quien adoptaría el nombre del Papa Francisco nombre en honor a San Francisco de Asís), fue electo como el Papa 266 de la historia; un personaje latinoamericano que inmediatamente anunciaba la apertura de los conceptos y divulgación de principios de la iglesia, acordes a los tiempos que se estaban viviendo. En menos de la mitad del tiempo que uso su predecesor, Francisco ya ha realizado el 50\% de los viajes de Benedicto XVI. Sus lugares han sido diversos la gran mayoría de ellos por motivos pastorales, bajo elementos de dignidad personal y justicia social que han sido profundamente divulgados, las Encíclicas del Papa Francisco han sido orientadas a la profundidad de temas como la sustentabilidad o el nuevo papel de la fe en la Iglesia Católica dentro de la globalización. La Carta Encíclica Lumen Fidei ${ }^{13}$, relata que la fe se veía como una luz ilusoria, que impedía al hombre seguir la audacia del saber. Este documento fue dedicado a los Obispos, Presbíteros, Diáconos, Consagrados y Fieles Laicos: "sin embargo, al hablar de la fe como luz, podemos oír la objeción de muchos contemporáneos nuestros. En la época moderna se ha pensado que esa luz podía bastar para las sociedades antiguas, pero que ya no sirve para los tiempos nuevos, para el hombre adulto, ufano de su razón, ávido de explorar el futuro de una nueva forma"(Bergoglio, 2013, p. Punto 2). La segunda Encíclica, emanada de la festividad del Pentecostés en 2015 fue intitulada Laudato Si, mi' Signore ${ }^{14}$. Esta Encíclica fue dedicada el cuidado y responsabilidad que tenemos los humanos respecto a nuestro planeta. Plantea temas tan fuertes y diversos como la contaminación y el cambio climático, la biodiversidad, el cuidado del agua y en particular ocupa un capitulo denominado el deterioro de la calidad de la vida humana y la degradación social: "hoy advertimos, por ejemplo, el crecimiento desmedido y desordenado de muchas ciudades que se han hecho insalubres para vivir, debido no solamente a la contaminación originada por las emisiones tóxicas, sino también al caos urbano, a los problemas del transporte y a la contaminación visual y acústica. Muchas ciudades son grandes estructuras ineficientes que gastan energía y agua en exceso. Hay barrios que, aunque hayan sido construidos recientemente, están congestionados y desordenados, sin espacios verdes suficientes"(Bergoglio, 2015, p. Punto 44). Los lugares que ya visitó el Papa Francisco

12- El anuncio de la renuncia oficial de Benedicto XVI fue hecho el 11 de febrero del 2013 citando motivos referentes a su edad.

13- Publicada en Roma el 29 de junio de 2013 en el marco de la Celebración del día de San Pedro y San Pablo.

14- Publicada en Roma el 24 de mayo de 2013 en el marco de la Celebración del día de Pentecostés. 
son Estados Unidos, Corea del Sur, Ecuador, Bolivia, Albania, Paraguay, algunas zonas de guerra africanas, México y Cuba. Para poder entender lo que representa una visita papal a cualquier nación, se utilizará el modelo de Kazancoglu y Dirsehan (2014), es una propuesta que devela la huella que deja en la experiencia de la marca ciudad este tipo de visitas por medio de elementos muy claros sobre los cuales se puede dirigir la reconstrucción de la marca de la ciudad. El modelo está basado en 6 categorías, 5 de las cuales hacen referencia a aspectos positivos de la marca mientras que una de ellas hace alusión a lo que pudiera interpretarse como la parte negativa o de riesgo de la localidad. Los estratos son la experiencia en las actividades sociales y de tiempo libre, la experiencia afectiva, la experiencia observable, la experiencia de los sabores, la experiencia de la naturaleza y por último la experiencia del disturbio de los sentidos. Desde el estudio de William (2001) con la teoría de mercadear el miedo explotando la naturaleza de los lugares donde han ocurrido eventualidades; pasando por la teoría de Trueman, Cornelius \& Killingbeck-Widdup (2007), Kaplan, Yurt, Burcu \& Kemal (2010) e inclusive Lucarelli \& Berg (2011) han elaborado estudios que han descifrado cómo las eventualidades negativas pueden ser útiles para el desarrollo de la marca ciudad y por lo tanto ser referentes en el desarrollo de programas del mercadeo de la ciudad. Todos los términos giran alrededor de la expresión "deleite citadino"15, y en un primer plano, la visita de alguien tan importante como el Papa Francisco debería incrementar el grado de lealtad del ciudadano a su ciudad. Cuba es un ejemplo muy relevante de como una visita distinguida puede contribuir al desarrollo de la marca país que luego propiciará en el largo plazo la marca ciudad y por ende reflejar en el mercadeo del lugar una distinción diferente. El proceso de construcción de una marca requiere de un plazo considerable (Dinnie, 2008), el forzar los resultados de la aplicación del mercadeo de nación a un corto plazo pudiera cercenar la posibilidad del desarrollo de la aplicación de la marca ciudad, por ejemplo para el desenvolvimiento de ciudades como La Habana. El proceso semeja un proceso de evolución natural donde la imagen y la visión del país se refleja en alguna otra territorialidad, "la reputación de los países, lo cual es totalmente aplicable a otros territorios como las ciudades o las comunidades, es como la imagen de marca de las empresas y los productos" (Alameda \& Fernández, 2012, p. 2). Al haber concluido su visita durante febrero de 2016, Cuba tiene la inusual distinción de ser uno de los pocos países a nivel mundial de haber sido visitado con especial atención por los últimos tres Papas. Como colonia española, Cuba adopto la fe católica. En 1959, antes del movimiento revolucionario cubano, la población practicante del catolicismo se estimaba en un $85 \%$ pero bajo el mando de Fidel Castro este número decayó hasta niveles del 50\%. Dos factores fueron vitales para mantener viva la llama de la religión, la Teología de la Liberación ${ }^{16}$ y la visita del Papa Juan Pablo II en 1998, de quien Castro expresó su respeto mencionándolo "como un hombre preocupado por los principales problemas del mundo de hoy"(Holland, 2009, p. 18). Una visita de corte Pastoral y que ayudaría en la mejora de las relaciones diplomáticas entre El Vaticano y Cuba. La nación caribeña desde 1959 ha cargado con el estigma de ser uno de los pocos países socialistas que quedan en el mundo, y compaginado con esta etiqueta, se puede analizar el bloqueo económico que esta sobre la isla desde el 7 de febrero de 1962 con la Proclama Presidencial 3447 firmada e impuesta por el presidente John Kennedy de Estados Unidos (Editor Elmar, 2013). Esta restricción comercial sin precedentes -y con una actualidad muy cuestionada- ha

15- Expresión que traduce el término de la teoría en ingles que refleja la expresión de "likeability for the place".

16- Corriente de la escuela católica que fue desarrollada por sacerdotes con un enfoque radical basado en los principios marxistas impulsaron fuertemente la práctica de la religión. Filosofía fuertemente adoptada en centro y Sudamérica. 
hecho que la sociedad cubana viva en un aislamiento como nación que se puede describir como insólito; Juan Pablo II en el discurso a su llegada a la Habana en 1998; dijo con claridad sus intenciones de mediar por Cuba ante el ascetismo que se vivía en la isla, reflejando un estilo de vida con pobreza, una sociedad oprimida y con un modelo de desarrollo anticuado; era necesario abrir las puertas de la modernidad, "que Cuba se abra al mundo con todas sus magníficas posibilidades, y que el mundo se abra a Cuba"(Vincent \& Aznarez, 1998). En nuestros días, China, Corea del Norte y Cuba representan estos tiempos donde los ciudadanos aun pelean por sus derechos básicos e inclusive tienen un alto porcentaje de retos contra temas como la corrupción, los pendientes políticos, desafíos macroeconómicos que sin duda son puntales para el desarrollo integral de las naciones y de ciudades en particular. Al momento de estar en La Habana, Juan Pablo II sentenció de forma magistral la consecuencia de un estilo de vida indefinido para la sociedad cubana con el estado de aislamiento impuesto, ya que en la actualidad, no hay nación que este de pie en el aislamiento"(Holland, 2009). Por lo tanto, a los cubanos no se les puede negar los contactos con otras personas necesarias para el desarrollo cultural, social y económico de su país y ciudades, especialmente cuando el aislamiento impuesto golpea indiscriminadamente a la población, haciendo aún más difícil para los débiles disfrutar de lo esencial para llevar una vida decente - tales como la comida, la salud y la educación" (Holland, 2009, p. 19). Esta fue una de las demostraciones más contundentes de que la imagen de Cuba estaba por reeditarse, un catalizador energizante para brincar de la realidad a la nueva propuesta de integración global del universo cubano. Catorce años despues de esta visita, Benedicto XVI tendría su turno para solicitar la apertura de la isla, "se elimine, en la dimensión nacional e internacional, «posiciones inamovibles y los puntos de vista unilaterales», proponiendo continuar en el campo del diálogo paciente y sincero que genera esperanza”(Ortega y Alamino, 2012, p. 48). Fidel Castro reconocería: "la única vía para atenuar el creciente malestar popular es la de profundizar los cambios económicos, políticos y sociales. La obstinación en mantener un modelo fracasado que “...ya no funciona ni para nosotros..." (Espinosa Chepe, 2012). Tres fructíferos días de visita papal por parte de Benedicto XVI, aquella gira de finales de marzo de 2012 serviría de precedente para las buenas nuevas; se asomaba así la oportunidad de crear el concepto y desarrollo de la marca nación con la oportunidad de a la par construir en algún momento el desarrollo de la marca ciudad para La Habana. Entretanto, la asistencia de más de 300,000 ${ }^{17}$ personas a una misa masiva fue un mensaje claro de que la manipulación religiosa en la isla era una medida de control que paulatinamente se iba difuminando. El papel de Juan Pablo II había sido abrir la puerta de la esperanza, Benedicto era el constructor de las vías para instalar una nueva faceta de Cuba para el mundo y tan solo faltaba quien tenía que echar a andar los engranajes, nadie más que Francisco y su propuesta de revolucionar la Iglesia Católica y el mundo, Cuba no podía estar fuera de la ecuación. El día 17 de Diciembre de 2014, Cuba y Estados Unidos harían el anuncio del año; reestablecerían relaciones diplomáticas en el corto plazo, 54 años de distanciamiento habían sido erosionados con una fuerte disposición política y el trabajo operativo de Jorge Bergoglio, Su Santidad Francisco; quien como buen operador de paz, había hecho ya acercamientos en lo particular con Raúl Castro y Barack Obama invitándolos a reconciliarse como naciones y reanudar sus trabajos diplomáticos; el 20 de julio de 2016 lo que casi 20 años atrás había solicitado Juan Pablo II y que tan sólo 4 antes Benedicto XVI había visionado, daba fruto en la persona de SS Fran-

17- Se estima que, en la Plaza de la Revolución, la misa masiva congrego a más de 300,000 personas para oír el mensaje de Su Santidad Benedicto XVI. 
cisco; Cuba abría su representación diplomática en Washington y a su vez La Habana recibía a la representación estadounidense. Un gran paso para dar un realce a la identidad cubana y el primer atisbo de marca nación, la apuesta de Francisco era la de la libertad de la opresión en muchos sentidos de los bloqueos cubanos, abrir el mundo cubano al universo de las posibilidades mundiales. Una clara intención de lo anterior puede ser la visita de Su Santidad Francisco en septiembre de 2015 a la isla su escala rumbo a los Estados Unidos. Un momento donde aprovechó para recordar las posibilidades infinitas del desarrollo cubano si el bloqueo era levantado. Como ejemplo tomo a los inversionistas en bienes raíces que, apegándose a la Ley 118 referente a la Inversión Extranjera(Cámara de Comercio de la República de Cuba, 2015) ya estaban comercializando el sector turístico y de propiedades en Cuba, muestra irrefutable del incipiente desarrollo de identidad que servirá en el futuro para la correcta imagen de la isla en el contexto global; la siguiente parada será posicionar localidades como La Habana, Cienfuegos, Santiago de Cuba, Camagüey, Guantánamo o Pinar del Río; inclusive tomar locaciones como Varadero, Playa Esmeralda, Ancón o Guanabo como los potenciales destinos turísticos que a nivel mundial y bajo un correcto mercadeo de sus atractivos puedan llegar a ser una revolución turística. Los simbolismos de la apertura cubana y su aportación mundial no pararon ahí. Previo a su visita pastoral en México en 2016, el Papa Francisco hizo una escala en La Habana para entrevistarse con el Patriarca de la Iglesia Ortodoxa Rusa, Cirilo I. La primera reunión en más de 1,000 años; una ausencia total de comunicación entre Roma y Moscú; desde la gran ruptura religiosa en $1054^{18}$ el silencio era la conversación entre ambas fracciones de la religión católica. En este encuentro el Papa Francisco le dijo al Patriarca Cirilo "Coincidimos en que la unidad se hace caminando", por lo que trabajaremos juntos" y afirmo de la nación caribeña "Si Cuba sigue así, será la capital de la unidad"(CNN Español, 2015); un auténtico espaldarazo a la creación de la marca nación. De esta forma ya estaba planteado una nueva realidad cubana, aquella que incluye la construcción y develación a nivel internacional de la marca caribeña, así como un programa de mercadotecnia del lugar que vaya acorde a las nuevas necesidades, tarde o temprano no habrá más bloqueo económico y Cuba puede irse preparando para nuevos e innovadores tiempos. Al menos para la isla caribeña, las visitas Papales han logrado poner en el plano internacional a Cuba, desarrollaron conceptos híbridos de marca nación y marca ciudad. Ahora el turno fue para Ciudad Juárez y su estigma de la ciudad más violenta del mundo, si bien en Cuba había un bloqueo económico, en la ciudad fronteriza se vive un bloqueo social sin precedentes; uno que tenía en cautiverio a la potente marca que representa en el contexto económico internacional el nombre Ciudad Juárez y que al igual que la isla tuvo el privilegio de contar con la presencia, discursos y mística de una visita papal, de Francisco, el revolucionario de la grey católica en los tiempos digitales.

\section{Ciudad Juárez, ¿Es la visita papal de Su Santidad Francisco la pieza que falta en este complejo rompecabezas de la marca ciudad?}

En mayo de 2014 el Obispo de Ciudad Juárez envió una carta a El Vaticano invitando a la ciudad a SS Francisco como precedente a su visita a los Estados Unidos, el resultado fue una negativa ante la pe-

18- Se refiere el movimiento que origino la separación entre las fracciones de la religión católica. Un grupo quedo bajo el liderazgo del Obispo de Roma mientras que la otra parte vivió el liderazgo de la Iglesia Ortodoxa. 
tición. En el verano de 2015, fue el turno de las autoridades gubernamentales de Ciudad Juárez quienes hicieron la propuesta de una visita y la respuesta fue, que en caso de tener una gira por México habría una consideración para la ciudad. Dos invitaciones con sabor a negación. Sin embargo, en noviembre de 2016 el Episcopado Mexicano recibió la noticia y confirmación de la visita papal a México en febrero de 2016; Ciudad Juárez junto a la Ciudad de México, San Cristóbal de las Casas, Tuxtla Gutiérrez, Ecatepec y Morelia serían las ciudades que serían visitadas por Su Santidad, la frontera cerraría el periplo de Francisco en su viaje a Mexico con irrestricto sentido pastoral. La cita con el destino fue marcada para el día miércoles 17 de febrero, un día histórico para Juárez por la presencia de tan distinguido visitante. El vocero oficial de la Diócesis de Juárez, Hesiquio Trevizo puntualizó en algún momento de septiembre de 2015, que en el caso de una eventual visita papal a Juárez esta significaría mucho para nuestra ciudad ya que cuando el Papa habla en un lugar su plática se hace extensiva a nivel mundial. La ciudad ha pasado por retos muy fuertes, desafortunadamente continúan los feminicidios ${ }^{19}$, es muy fácil el disponer de las vidas humanas por la violencia existente, el mundo de la inmigración que es lastimoso, la facilidad con la que se hace la trata de personas, el abuso infantil y muchas otras cosas"20. Para analizar la visita papal a Juárez es necesario voltear a ver el uso de las comunicaciones de tipo primario y secundario de las que se habla en el modelo de Kavaratzis (2014), esto para poder encontrar cómo reflejar estos conductos en el comportamiento de los ciudadanos que al final darán fuerza a favor o en contra a la forma terciaria de comunicación. Sin embargo, para analizar las consecuencias de esta visita pastoral es recomendable hacer uso también del modelo de Kazancoglu y Dirsehan (2014) con sus seis categorías de reconocimiento de la experiencia de una marca ciudad y así entender la dinámica creada alrededor de la visita y encaminarnos a determinar cuál fue el verdadero efecto de la visita del Papa Francisco en la creación y sustentamiento de la marca de la ciudad, reforzando los verdaderos alcances de la visita papal. A diferencia de Cuba, lugar en donde se hizo más por la aplicación de la marca país, en México se podía visualizar que Su Santidad hablaría muy fuerte a las autoridades, en especial de los retos que vive cada localidad que visitó, el enfoque era mas orientado al desasrrollo de marca ciudad. El modelo incluye 6 aristas como la experiencia del tiempo libre y la convivencia social, la experiencia afectiva por la ciudad, la experiencia observable, la experiencia a nivel degustación, la experiencia del entorno natural de la ciudad y finalmente aquellos factores que ayudan a crear experiencias perturbantes a los sentidos.

5.1. La experiencia de la vida social y el tiempo libre. Juárez es una ciudad con un dinamismo impactante que puede incluir hasta los tres turnos de trabajo que ofrece la maquiladora. La ciudad tiene más de 2,500 lugares para visitar, lugares como los bares, antros, salones para bailar o donde simplemente vas y te tomas una cerveza son indicadores de esta intensa actividad ${ }^{21}$. La ley seca, ${ }^{22}$ decretada a partir de los días de la visita papal fue un inhibidor de esta oportunidad de esparcimiento, la medida

19- Violencia de genero contra las mujeres.

20- Publicado en la edición impresa de El Diario de Juárez el 15 de octubre del 2015.

21- http://diario.mx/Local/2013-01-16_ff75c19f/transfieren-mas-de-mil-permisos-de-venta-de-cerveza-al-estado/ 22- Se le denomina así a la disposición gubernamental que prohíbe vender durante un determinado tiempo cualquier bebida que contenga un grado de alcohol, ya sea en establecimientos de dispendio de bebidas, restaurants o bares. 
tuvo efecto entre el 16 y el 18 de febrero. Con esta disposición legal los rubros comerciales más favorecidos fueron los hoteles y los restaurantes cuyo ingreso y desarrollo fue tasado en los $\$ 45,000,000$ de pesos o a la par del tipo de cambio $\$ 2.6$ millones de dólares ${ }^{23}$. La ocupación hotelera en esos días fue en promedio de $97 \%$ con una población estimada en la ciudad de 2,000,000 de personas, cuando la población estimada de la ciudad es de solamente 1,300,000 habitantes ${ }^{24}$. También en la vecina ciudad de El Paso los paquetes que incluían dos entradas al SunBowl para la misa masiva costaron \$3,000 dólares, la renta incluía hospedaje por tres días. La visita estaría incompleta si no se llevaban un recuerdo de la visita, al menos tres tiendas "oficiales" fueron establecidas para tal propósito, pero sin más, la venta de artículos "piratas" fue un fenómeno que incluyo la venta de rosarios, mochilas, fotos, vasos, medallas, playeras todas ellas a precios módicos y con una notable afluencia en las principales avenidas y hasta en tiendas de supermercado que prefirieron la venta de estos artículos en lugar de los llamados "oficiales"25. Al final del día, en cualquier superficie y tamaño en la cual se pudiera explayar la imagen del Papa francisco podía representar un buen argumento de comercialización de la imagen. Incluso y debido a que los hoteles no tuvieron la suficiente capacidad de hospedaje, se desarrolló otra forma de negocio, muchas familias rentaron una habitación de sus casas o bien las terrazas para observar el tránsito de Su Santidad por las calles de la ciudad, no importaba que fueran solo 6 segundos, lo trascendente era verlo; el precio estaba justificado ${ }^{26}$. Así que desde este punto de vista, del factor del esparcimiento se puede enunciar que la visita de un personaje de esta talla si otorga beneficios para el establecimiento de marca aunque los efectos de la misma sean de muy corto plazo ${ }^{27}$; ya que de acuerdo a lo que la directora de turismo del gobierno estatal Irma Barragán comento "ni en un año de turismo con un esquema de constante promoción se pueden lograr los números que se dieron la visita del Papa Francisco en un solo día en la plaza"28. En el estado de Chihuahua el gobierno invirtió $\$ 40,000,000$ de pesos y obtuvo una derrama económica de $\$ 4,000,000,000.00$, un sorprendente éxito económico que encontró en la categoría de la experiencia social la justificación de la inversión de la visita Papal y que sin duda es fundamental para la reconstrucción de la marca. La falacia es que el desempeño económico no ha tenido un eco ni asociación en el seguimiento de la marca ciudad, la falta de seguimiento de los beneficios económicos han hecho que la visita papal este cada vez mas dirigida a ser parte del ancedotario de la ciudad, asi es como se pierde una oportunidad de ser reconocida como

23- Con la tasa del tipo de cambio de 17 pesos por dólar.

24- http://www.cbsnews.com/news/ciudad-juarez-registra-97-de-ocupacion-hotelera-por-visita-del-papa/

25- http://www.rumbodechihuahua.com/noticia.cfm?n=40890

26- http://www.rumbodechihuahua.com/noticia.cfm?n=40890

27- http://www.televisajuarez.tv/noticias/12039-cifras-de-visitantes-se-conoceran-la-proxima-semana

28- http://www.rumbodechihuahua.com/noticia.cfm?n=40890 
una de las ciudades en las cuales ha estado compartiendo sus mensajes el Papa Francisco.

5.2 La experiencia afectiva. Es la variable que más reto implica al momento de medir su potencial éxito. Es una plataforma de medición muy subjetiva, pero Instituciones como el Plan Estratégico de Juárez han logrado desarrollar índices de medición para esta categoría de acuerdo a sus encuestas de percepción que son difundidas año tras año. Es una iniciativa ciudadana que mide los elementos que afectan la calidad de vida en Juárez, basadas en estadísticas y percepciones (Plan Estratégico de Ciudad Juárez, 2015). El índice de Bienestar Subjetivo observa factores como la felicidad, la satisfacción de los servicios públicos, servicios de salud entre otros factores que dan una imagen completa del lugar. En el estudio de 2015 el índice registro un valor de 7.5 de 10 y en los últimos tres ha sido de 7.43, 757 y el de 7.5; 2012, 2013 y 2014 respectivamente. Otra base para medir este factor es la pregunta ¿Qué tan feliz es viviendo usted en Juárez? La respuesta obtuvo un 8.3, el 51\% declaró estar entre las categorías de feliz o muy feliz ${ }^{29}$. Esta es la percepción dentro de la ciudad, pero ¿Y la percepción creada por los visitantes? La prensa internacional venía buscando la noticia que afirmara o contraindicara el escandaloso seguimiento de Ciudad Juárez como una urbe violenta. El diario español El País, en su titular de febrero 17 anunció: "El Papa se despide de México visitando el infierno de Ciudad Juárez"30, o El Mundo, "Ciudad Juárez, el Papa en la ciudad del diablo", y ahonda más en su texto al citar que "la ciudad se convirtió en una alcantarilla donde se podía almacenar todo el desperdicio humano"31. Estas notas sensacionalistas son las que le han dado a Ciudad Juárez una connotación de ciudad fea y peligrosa, pero de acuerdo al Consejo Civil para la Seguridad Pública y Justicia Penal informó en su edición de enero 26 de 2016 la nueva lista con las 50 ciudad más peligrosas del mundo, y constató que "Juárez y Medellín, dos ciudades que habían dominado el ranking hasta hace 5 años dejaron ya de estar en la lista”(BBC Mundo, 2016). Si se hace una búsqueda en google de la leyenda "Ciudad Juárez mala" los resultados son de 514,000 resultados mientras que el buscador obtiene resultados para la leyenda "Ciudad Juárez bueno", los registros marcaran solo 360,000 impresiones. Con base en estos números era aún más importante la visión de la prensa internacional en el proceso de reconocimiento de marca para el reposicionamiento de la ciudad. Más de 1,500 periodistas solicitaron la acreditación de prensa, 1,007 acreditaron y finalmente 876 acudieron a la cita. Titulares como 'Comunidad en recuperación”; empleado por la reportera Lucia Cappuzi del periódico Avvenire, (la fuente oficial del Episcopado italiano) ilustraba "Juárez es una comunidad tan dañada pero plena de voluntad para vivir y reconstruirse"(Capuzzi,

29- Plan Estratégico de Juárez versión 2015.

30- Fue publicado en su edición digital con fecha de febrero 17.

31- Esta información fue publicada en su edición impresa el día 17 de febrero. 
2016). Y también apuntó: "gracias por hacer lo que hacen, por no rendirse ante estos monstros. Sepan que no están solos, hay personas en todo el mundo que tienen su mirada puesta en ustedes, incluso el Papa Francisco que con este viaje les está diciendo que esta con ustedes, con sus víctimas, con sus inmigrantes, con aquellos que sufren. No se den ustedes mismo por vencidos"32. Uno de los objetivos colaterales al margen del contenido religioso era reflejar que los habitantes de la ciudad están contentos con la ciudad y la disfrutan, la aman, sienten orgullo y felicidad de vivir en "la frontera donde debe vivir Dios"33. Desde esta categoría se puede inferir la utilidad de la visita papal para reconfigurar la imagen de la ciudad más violenta del mundo, sin embargo, el misticismo que rodea la personalidad de Su Santidad no es suficiente para transformar la imagen de la ciudad, es un elemento muy fuerte para desarrollar las bases de una reedificación de la marca hacia una imagen global y no violenta. Al igual que en el renglón económico, las Instituciones encargadas de darle seguimiento a la visita papal han fallado de manera notoria, han exhibido un alto grado de miopías mercadológicas, uno de los 5 típicos errores de la aplicación de la marca ciudad; no hubo una transferencia afectiva de un motivo racional (Herstein, Berger, \& Jaffe, 2013). Inclusive la misma Diócesis de Juárez ha desperdiciado la oportunidad de hacer sentir de una manera más sensible características de orgullo y pertenencia a una comunidad que tuvo la fortuna de ser seleccionada como parte de la gira papal a México en 2016.

5.3 La experiencia observable. La forma más fácil de identificar los beneficios de la visita papal. Uno de los aspectos más críticos para los participantes citadinos se convirtió en un beneficio fácilmente observable ${ }^{34}$. Esta categoría se define como la arquitectura, el misticismo, la riqueza de la historia del lugar y los lugares de interés que tiene el mismo. Juárez es muy diferente al resto del país, no posee un urbanismo como el del centro del país: "la arquitectura en esta frontera se inventa frente a la diversidad multicultural de una ciudad que no termina por asimilar el pasado, que construye y destruye, que improvisa y descubre, que se relaciona con lo que tiene enfrente, ciudad que elabora su historia, su propia historia, a partir de cada día. Aquí no existen fastuosos monumentos, grandes palacios o catedrales suntuosas"(Staines Orozco, 2008, p. 52). Aun así, la ciudad goza de diferentes puntos interesantes para visitarla ${ }^{35}$. La visita del Papa agregó otros cuatro atractivos a la ciudad. La cárcel que está adentro del penal, la remodelación del Seminario, el Altar denominado "El Punto" y la

32- Esto fue recopilado por Presencia, el periódico local de la Diócesis Católica al acudir a un encuentro entre la periodista italiana y los grupos vulnerables de la sociedad.

33- Es un fragmento de la canción "Juárez es el número uno” del famoso artista Juan Gabriel, una persona icónica del desarrollo artístico de Ciudad Juárez.

34- De acuerdo a Plan Estratégico, el mejoramiento de las calles es el peor de los servicios públicos al obtener una calificación de 5.8 en el informe de 2014.

35- Se hace referencia a la página 10 donde puede encontrar más detalles de este punto. 
cruz que se instaló justo al lado del Rio Bravo y que ha sido denominada como la "Cruz del Migrante". Tanto el Seminario como la Capilla del Cereso son puntos a los cuales no tiene acceso la población en general, tienen carácter privado. El Punto es un proyecto ambicioso para el desarrollo social de la localidad. Fue creado por los arquitectos Jacques Herzog y Pierre de Meuron, los mismos que construyeron el estadio nacional de Pekín con motivo de los Juegos Olímpicos en 2008 y que bautizaron como "El Nido del Pájaro". El proyecto es colosal, mide 62,000 metros cuadrados y representa una inversión de aproximadamente $\$ 70$ millones de dólares ${ }^{36}$ y su objetivo es desarrollar un espacio público que pueda ser utilizado para desarrollar eventos artísticos, religiosos, musicales, talleres e inclusive hospedaje para migrantes. La primera parte ya fue concluida y consistió en el Altar, el lugar donde el Papa Francisco ofreció la misa masiva en la frontera y que actualmente es utilizado para misas dominicales además de ejercer el papel de atracción turística a los visitantes de la frontera. Al lado, se encuentra majestuosa la Cruz del Migrante. Una estructura cuyo peso esta ponderado en 400 kilogramos y una estatura de 6 metros. Es un simbolismo pleno, tiene tres alegorías de la migración; el signo familiar de los Scalabrinianos, la flor negra de los Dominicos (ambos de la casa del migrante de la ciudad) y la estrella de Nuestra Señora de Guadalupe, tiene los cuatro puntos cardinales como una muestra de la guía que reciben los migrantes ${ }^{37}$. Este punto turístico esta por ser removido, a pesar de que la prensa internacional lo reportó como una de las más fuertes representaciones de la visita papal, una atracción arquitectónica y una referencia de reflexión y oración mundial por los migrantes en especial para todos aquellos que han muerto en su intento por cruzar a los Estados Unidos de forma ilegal. En Ciudad Juárez la composición religiosa es diferente al resto del país, se reporta un índice de catolicismo del $83.9 \%{ }^{38}$. El crecimiento en la frontera de credos no católicos ha aumentado de forma constante en la última década, evangélicos, protestantes y ateístas han logrado alterar la tradición católica fronteriza, de tener un $81.57 \%$ de la población devota de la religión católica, hoy sólo es el $69 \%$ de la misma ${ }^{39}$. El reto de Su Santidad Francisco en la visita a la frontera era también revitalizar un misticismo católico menguante ante la entrada y proyección de otros credos incluyendo el culto a la Santa Muerte. Este ícono de los tiempos de la violencia en las ciudades, tiene un estimado de 12 millones de practicantes, en Ciudad Juárez tienen por lo menos 3 centros de adoración. La visita papal fue del tipo pastoral no de Estado, de tal forma que los mensajes emitidos en las diversas homilías fueron del tipo reflexivo y no de acuerdos sociales, económicos o políticos. En la ciudad, el Papa Francisco

36- http://diario.mx/Local/2013-03-19_09f46e14/el-punto-un-proyecto-de-primer-mundo-para-juarez/

37- http://nortedigital.mx/llega-a-juarez-cruz-de-los-migrantes/

38- De acuerdo a INEGI 2010.

39- Publicado por Diario de Juárez en abril 20 del 2015 como parte de un reportaje editorial referente a la religión en Ciudad Juárez. 
habló en 4 puntos con mensajes estratégicos; la bienvenida en el aeropuerto, la visita a la cárcel, el mundo del trabajo y finalmente la misa masiva justamente al lado del borde fronterizo con los Estados Unidos. Mensajes muy directos para la exposiciónreconstrucción de la marca ciudad, habló sin tapujos ni amarres de la problemática de la frontera. En la cárcel, "la reinserción social comienza insertando a todos nuestros hijos en las escuelas, y a sus familias en trabajos dignos, generando espacios públicos de esparcimiento y recreación, habilitando instancias de participación ciudadana, servicios sanitarios, acceso a los servicios básicos, por nombrar solamente algunas medidas. Ahí empieza todo proceso de reinserción”(ACI Prensa Vaticana, 2016, p. 75). En el encuentro con el mundo laboral en el Colegio de Bachilleres ${ }^{40} \mathrm{Su}$ Santidad ideó su propia visión de Ciudad Juárez: “¿Qué quiere dejar México a sus hijos? ¿Quiere dejarles una memoria de explotación, de salarios insuficientes, de acoso laboral o de tráfico de trabajo esclavo? ¿O quiere dejarles la cultura de la memoria de trabajo digno, del techo decoroso y de la tierra para trabajar? Tres T. Trabajo, techo y tierra. ¿En qué cultura queremos ver nacer a los que nos seguirán? ¿Qué atmósfera van a respirar? ¿Un aire viciado por la corrupción, la violencia, la inseguridad y desconfianza o, por el contrario, un aire capaz de generar alternativas, generar renovación o cambio?" (ACI Prensa Vaticana, 2016, p. 75). La misa masiva en El Punto fue el punto clave de la reconstrucción de la marca al hacer una analogía con la mística ciudad de Nínive; "Nínive, una gran ciudad que se estaba autodestruyendo, fruto de la opresión y la degradación, de la violencia y de la injusticia"(ACI Prensa Vaticana, 2016, p. 81). Y continua con la comparación, "Nínive será destruida» (Jon 3,4). Ve, ayúdalos a comprender que, con esa manera de tratarse, regularse, organizarse, lo único que están generando es muerte y destrucción, sufrimiento y opresión. Hazles ver que no hay vida para nadie, ni para el rey ni para el súbdito, ni para los campos ni para el ganado. Ve y anuncia que se han acostumbrado de tal manera a la degradación que ha perdido la sensibilidad ante el dolor"(ACI Prensa Vaticana, 2016, p. 81). Al momento de hablar de los migrantes externó su preocupación por las personas esclavizadas, los que han pasado por un secuestro, los que ven como el fruto de su trabajo es arrebatado sin remordimientos por extorsionadores: "esta tragedia humana que representa la migración forzada hoy en día es un fenómeno global. Esta crisis, que se puede medir en cifras, nosotros queremos medirla por nombres, por historias, por familias. Son hermanos y hermanas que salen expulsados por la pobreza y la violencia, por el narcotráfico y el crimen organizado"(ACI Prensa Vaticana, 2016, pp. 82-83).Y la última reflexión sobre la riqueza de nuestra nación la dio minutos antes de abordar el avión que lo llevaría de regreso a Roma "La que siempre sorprende, México es una sorpresa... La noche nos puede parecer enorme y muy oscura, pero en estos días he podido constatar que en este pueblo existen muchas luces que anuncian la esperanza... muchos hombres y mujeres, con su esfuerzo 
de cada día, hacen posible que esta sociedad mexicana no se quede a oscuras"(ACI Prensa Vaticana, 2016, pp. 85-86). La categoría de lo observable en el modelo de Kazancoglu y Dirsehan (2014) dio la impresión de ser incluyente, no era un mensaje para católicos, era un mensaje para todos aquellos que quisieran participar en la argumentación de la reconstrucción de la marca ciudad, por si sola la visita no es la panacea de los males ni ausencias que sufre la ciudad, sin mucho puede llegar a ser un impulsor de proporciones globales para renovar la imagen y fomento de la identidad e imagen del lugar, ambos conceptos puntuales para detallar lo que se quiere dar a conocer tanto al mercado interno como externo de las condiciones del lugar de estudio.

5.4 La experiencia del sabor. Esta categoría no tuvo algún ajuste. Los restaurantes no hicieron ningún tipo de esfuerzo por presentar algún tipo de nueva comida en honor a Su Santidad.

5.5 La experiencia de la naturaleza. También en esta categoría del modelo no se han percibido afectaciones o beneficios importantes. La estrategia fue de modernizar y dar arreglo al camino que tendría el Papa Francisco en la ciudad, en especial aquel que recorrería camino a la misa masiva de El Punto. Actividades de mantenimiento, plantación de algunos árboles y el remodelamiento de camellones fueron las actividades realizadas. El real reto fue la recolección de basura en los puntos en los que estuvo el Papa Francisco, más de 500 toneladas de basura fueron recogidas de los puntos $^{41}$. Es necesario comentar que hay una insatisfacción entre la población por la disponibilidad de áreas verdes en los espacios públicos, la calificación de su calidad es de 6.19 (Plan Estratégico de Ciudad Juárez, 2015), de esta forma el reto para el Cabildo y autoridades de gobierno de la ciudad fue hacer más atractivo el lugar acorde a su naturaleza desértica.

5.6 La experiencia del disturbio sensorial. Tal y como fue planeado, la visita del Papa Francisco no incluyó algún lugar marginal o que tuviera un aspecto negativo a la percepción. Toda la ruta papal fue diseñada para facilitar la logística de la actividad. Aun y cuando la ciudad enfrenta graves rezagos en infraestructura urbana, uno de los puntos mejor evaluados por la sociedad fue el manejo de los desperdicios, un 8.54 de 10 (Plan Estratégico de Ciudad Juárez, 2015). De esta manera se puede afirmar que es un problema menor al que en comparación representa el agua estancada, la contaminación visual o el intenso ruido de la vida nocturna; tan solo esta situación provoca de 6 a 20 reportes diarios ${ }^{42}$.

41- http://www.radioformula.com.mx/notas.asp?Idn=571789\&idFC=2016

42- http://nortedigital.mx/reportan-vecinos-quejas-por-ruido-pero-no-los-pelan/ 
El análisis de las seis categorías de Kazancoglu y Dirsehan (2014) son una base de exploración y no debe ser un elemento concluyente del éxito o fracaso de la marca ciudad por la visita de una personalidad distinguida, su conceptualización debe generar oportunidades estructurales para enriquecer la definición de la experiencia del lugar y por lo tanto agregar elementos a la redefinición de la marca y sacar un provecho tangible de la visita de personajes distinguidos como presidentes, artistas, deportistas o líderes de una especialidad como por ejemplo el Papa Francisco. Es importante agregar variables de estudio como sustentabilidad, participación cívica, programas de gobierno, balance social, arraigo por la ciudad entre otros. El no contemplar este tipo de visitantes es una debilidad del modelo, hay que enriquecer los modelos de aprovechamiento de eventos de la ciudad donde se refleja el estudio de visitas distinguidas; el modelo de Metaxas (2012) es uno de los pocos que existen en la literatura de la marca ciudad que hace alusión a este apartado. Hay una oportunidad poder incluir en los modelos de estudio de marca país y marca ciudad, este tipo de actividades que estudien el impacto que puede tener en el desarrollo global del lugar elevando su nivel de vida vía experiencia del ciudadano o bien por el incremento de flujo de inversiones al lugar.

\section{Conclusión}

Hay una diversidad de herramientas para analizar la visita de Su Santidad a Juárez y se puede lograr una referencia que al igual que en el caso de Cuba, la visita de una personalidad distinguida no es la definición de la marca ciudad; genera elementos que coadyuvan al reforzamiento del concepto, pero no será automáticamente la definición de la misma. Sus mensajes pueden ser catalizadores del entendimiento, pero no la solución del reto de definir la esencia de la marca ciudad, incluso como en el caso de Cuba tampoco es la definición de la marca nación y es muy poco factible que en el largo plazo sea la definición de la marca ciudad de La Habana por mencionar una de sus ciudades. Las visitas de personajes distinguidos deben ser usadas como un elemento de desarrollo y reforzamiento para la marca y asegurar mecanismos de seguimiento para mantener la dinámica creada por este tipo de visitas. Al final, jugará un papel importante cuando las dimensiones personales de la experiencia de la ciudad más el fortalecimiento de la dinámica social y económica de la ciudad, menos el riesgo de la experiencia citadina logre redefinir las condiciones de la integración del concepto de marca ciudad y solamente así podrán aspirar modelos de marca ciudad (como Juárez) para ganar una preponderancia relativa en un ambiente globalizado. Es importante analizar los modelos de Kavaratzis (2014), Kazancoglu and Dirsehan (2014), así como reflexionar sobre los potenciales errores de marca ciudad que se mencionan en los estudios de Herstein, Berger and Jaffe (2013), como una disciplina importante para reducir las imprecisiones en un tema especialmente sensible acerca de modelos de desarrollo social; las inconsistencias en las acciones derivadas del estudio de las condiciones económicas, sociales y políticas que dan como resultado la factibilidad de condiciones para la aparición de situaciones derivadas del narcotráfico y su violencia; ambas condiciones laceran y coartan el potencial desarrollo de la marca ciudad. Incluso, modelos sobre atributos de la ciudad (Muñiz, 2011), o la teoría de desarrollo de proyectos para el correcto mercadeo de las ciudades (Martínez, 2014), deben ser integrados para dar una solución integral al reto tan complejo que representa crear y sustentar una marca ciudad cuando el desarrollo económico no se está respaldado 
por el desarrollo social, estas circunstancias favorecen el calentamiento social; los resultados pueden ser la falta de arraigo en la ciudad y la consecución de una marca débil en el desarrollo de la globalización lo cual inevitablemente puede concluir en un estado de necrópolis; esta ha sido una tendencia que ha sido repetida en los últimos 50 años y cuyo mejor ejemplo lo podemos visualizar en la ciudad de Detroit en Estados Unidos; aunque analizando el fenómeno Ciudad Juárez las condiciones prevalecientes indican que si no se llevan a cabo las actividades correspondientes la marca ciudad terminara siendo arrastrada a la anarquía que implica la realidad de una necrópolis. Aun así, el bagaje social que representa la visita del Papa Francisco a un lugar, puede generar una personalidad atractiva vía actividades de anfitrionismo por la ciudad, corregir problemas de estrategia para la percepción del lugar, una nueva forma de administrar el tiempo libre y de restituir el daño en el tejido social, dar amplia experiencia en el uso correcto de los elementos del modelo de comunicación para alimentar el conocimiento, el compromiso y la preocupación de los actores que disfrutaran y usaran el espacio público llamado ciudad. Es solamente la piedra angular sobre la cual se pueden hacer planteamientos de una nueva definición de marca ciudad, la visita del Papa Francisco a la ciudad es un importante revulsivo y catalizador del desarrollo de marca, pero no puede ni debe ser utilizado y mucho menos conceptualizado como el principal argumento para rehacer la marca ciudad. Esta condición sólo se logrará si desarrollamos una combinación de estrategias en las que se involucren de manera activa, la iniciativa privada, la academia, el gobierno y la sociedad. Es lo que se ha dado a llamar la creatividad sinérgica, la integración y el entendimiento para dar un mayor realce competitivo a las ciudades (Morte et al., 2005). Los eventos, situaciones y personas no tienen el poder por sí solas para desencadenar movimientos de desarrollo de marca ciudad; los involucrados en la construcción de la marca ciudad deben amalgamar y dirigir los esfuerzos de manera integral para generar de manera puntual las condiciones de la marca ciudad y generar una identidad, una imagen y por supuesto los elementos racionales y emocionales que son los activos principales de la constitución de la marca, al final del día si los elementos amalgaman el resultado conductual de una marca ciudad tiene que ser el arraigo y el amor por la ciudad. Como fin último de la herramienta de la marca ciudad debe ser la felicidad de los actores sociales que conviven en la ciudad, es ver por el "bien colectivo de toda la comunidad" (Alameda \& Fernández, 2012, p. 10).

\section{Referencias}

ACI Prensa Vaticana. 2015. Viajes apostólicos.

https://www.aciprensa.com/juanpabloii/viajes/\#8/. (1 de febrero de 2015)

ACI Prensa Vaticana. 2016. Discursos del viaje apostólico a México en febrero 2016. https://www.aciprensa.com/noticias/todos-los-discursos-homilias-y-mensajes-del-papa-francisco-en-mexico-53969/. (17 de febrero del 2016)

American Marketing Association. 2011. Dictionary. https://www.ama.org/resources/Pages/Dictionary. aspx?dLetter=B4. (8 de agosto de 2011)

Balencourt, Amélie y Antonio Curado. 2012. City marketing? How to promote a city? Umea: Umea School of Business.

BBC Mundo. 2016. Seguridad, justicia y paz. http://www.seguridadjusticiaypaz.org.mx/temas-de-in- 
teres/internacional/1358-caracas-sobrepaso-a-san-pedro-sula-como-la-mas-violenta-del-mundo/. (26 de enero del 2016)

Bergoglio, Jorge. 2013. Encíclica Lumen Fidei. Roma: Librería Editrice Vaticana.

Bergoglio, Jorge. 2015. Encíclica Laudato Si. Roma: Tipografía Vaticana.

Brandoctor Consultants. 2011. Brandoctor Methodology. http://brandoctor.com. (12 de agosto del 2016) Cámara de Comercio de la República de Cuba. 2015. Portafolio de oportunidades para la inversión extranjera. La Habana: Cámara de Comercio de la República de Cuba.

Capuzzi, Lucía. 2016. Reporta periodista italiana realidad de Juárez por visita papal. http://presencia. digital/2016/02/17/reporta-periodista-italiana-realidad-de-juarez-por-visita-papal/. (17 de febrero del 2016).

Castañeda, Cecilia. 2015. Las lecciones de Ciudad Juárez. Ciudad Juárez: Hibribooks.

Castillo-Villar, Fernando.2016. Alcances y límites de la marca ciudad en la gestión de la imagen de la ciudad. Revista venezolana de Gerencia, 21(73): 157-171.

CNN Español. 2015. La unidad se hace caminando: Francisco y el Patriarca Ruso. http://expansion. $\mathrm{mx} /$ economia/2016/02/12/papa-francisco-viaje-cuba-mexicoiana-realidad-de-juarez-por-visita-pa$\mathrm{pal} / 2015$. (2 de febrero de 2015).

Dinnie, Keith. 2008. Nation Branding, concept, issues, practice. Oxford: Elsevier.

Echeverri, Lina. Rosker, Eduardo. 2011. Diferencias en la construcción de marca país: Canadá y Colombia. Revista virtual Universidad Católica del Norte, (33): 1-29.

Editor Elmar. 2013. John F. Kennedy. http://www.cubavsbloqueo.cu/es/john-f-kennedy-d. (10 de septiembre del 2013)

El Devenir Staff. 2011. Anuncian Plan de Movilidad Urbana para Ciudad Juárez.

http://devenir.com.mx/diario/index.php?option=com_content\&view=article\&id=4990:-anuncianplan-de-movilidad-urbana-para-ciudad-juarez\&catid=43:el-estado\&Itemid=57. ( 2 de febrero del 2011) Espinosa, Oscar. 2012. La visita del Papa Benedicto XVI a Cuba. http://www.cubaencuentro.com/cuba/ articulos/la-visita-del-papa-benedicto-xvi-a-cuba-275590/. (4 de mayo del 2012)

Esquivel, Jesús. 2012. Juárez, símbolo de la mortandad. http://www.proceso.com.mx/324640/324640juarez-simbolo-de-la-mortandad

(8 de noviembre del 2012)

Farworkers.org. S.f. La pisca de algodón. http://www.farmworkers.org/palgodon.html (s.f.)

Flores, Raúl. 2013. Crónicas del Siglo pasado. Ciudad Juárez: Universidad Autónoma de Ciudad Juárez. Florida, Richard. 2002. The Rise of the Creative Class. Washington Monthly: 1-12.

Gobierno Municipal de Ciudad Juárez. 2013. Plan Municipal de Desarrollo 2013-2016. Ciudad Juárez: Gobierno Municipal de Ciudad Juárez.

Harrison, John y Michael Hoyler. 2014. Megaregions: Foundations, Frailties, Futures. GaWC Bulletin Research, 434: 1-20.

Holland, Clifton. 2009. Enciclopedia de grupos religiosos en Las Américas y la Península Ibérica, la religión en Cuba. San Pedro, Costa Rica: Prolades.

Kaplan, Melik. Yurt, Oznur. Burcu, Guneri. Kemal, Kurtulus. 2010. Measurements of brand personality for city brands. European Journal of Marketing, 44: 1286-1304.

Kavaratzis, Mihalis. 2014. Model: City branding communication model. European Institute for Brand 


\section{Management: 1-2.}

Kazancoglu, Ipek y Dirsehan, Taskin. 2014. Exploring brand experience dimensions for cities and investigating their effects on loyalty to a city. Journal Business and economics research, 5: 17-37.

Limas, Myrna. 2011. Crisis en Ciudad Juárez, Chihuahua: desordenes y repercusiones en el desarrollo desde una perspectiva de género. Ponencia presentada en el Congreso de la Asociación Mexicana de Estudios del Trabajo, Mérida.

Lucarelli, Andrea y Berg, Per Olof. 2011. City branding: a state-of-the-art review of the research domain. Journal of Place Management and Development, 4(1): 9-27.

DOI: http://dx.doi.org/10.1108/17538331111117133

Martínez, José. 2014. A methodological proposal to evaluate a city image through associative maps. Cuadernos de Gestión, 14: 75-96.

\section{DOI: http://dx.doi.org/10.5295/cdg.120361jm}

Metaxas, Theodore. 2012. Planning, managing and implementing place/city marketing effectively: review and discussion of the last 25 years Munich Personal RePec Archive. 4: 1-23.

Muñiz, Norberto. 2011. City marketing and place branding: A critical review of practice and academic research. Journal of Town and City Management, 2: 369-394.

Morte, Pablo. Bujedo, Nestor. López, Rafael. Fernández, Francisco. 2005. Marca Territorio. Grupo Mibalia, 2: 1-67.

Ortega y Alamino, Lucas. 2012. La visita de un Papa conciliador y sus frutos. 30 Giorni: 48-53.

Plan Estratégico de Ciudad Juárez. 2015. Informe Así Estamos Juárez 2015. Ciudad Juárez: Plan estratégico de Ciudad Juárez.

Reynolds, Terry. 2011. The rise and fall of native communities at the Old El Paso del Norte Mission. http://www.donaanacountyhistsoc.org/HistoricalReview/2011/HistoricalReview2011.htm (s.f.)

Saffery, Alan. 2010. Success stories in city branding campaigns. Georgia: Economic Prosperity Institution. Salas, Jesús. 2014. Sinatra, Liz Taylor y Marilyn visten los 148 años del Registro Civil. Ciudad Juárez. http://diario.mx/Local/2014-07-25_0e0be89a/sinatra-liz-taylor-y-marilyn-visten-los-148-anos-del-registro-civil/. (25 de julio del 2014).

Sandoval, Lidia y Peña, Leticia. 2005. Historia del cabaret y vida nocturna como transformadores de la identidad cultural en el centro de Ciudad Juárez. http://www.rniu.buap.mx/enc/pdf/xxxiii_m4_sandovalr.pdf (s.f.)

Scheel, Carlos.Pineda, Leonardo. 2014. Innovacities. Monterrey: UTADEO.

Schwab, Klaus. Sala-i-Martín, Xavier. 2015. Global Competitiveness Index (GCI). Geneva: World Economic Forum.

Staines, Eliade. 2008. Ciudad Juárez: arquitectura, memoria y olvido. Archipiélago, revista cultural de nuestra América, 16 (62):52-55.

Vincent, Mauricio y Aznárez, Juan. 1998. Juan Pablo II: «Que Cuba se abra al mundo». http://www.udel. edu/leipzig/texts4/elb22018.htm/ (22 de enero de 1998).

William, Neill. 2001. Marketing the urban experience, reflections on the place of fear in the promotional strategies of Belfast, Detroit and Berlin. Urban Studies, 38: 815-828. DOI: http://dx.doi. org/10.1080/00420980125183. 